\title{
Capacita SUAS no Pará: uma abordagem a partir da diversidade territorial
}

\author{
Capacita SUAS in Pará: an approach from the territorial diversity
}

\author{
Silvia Aline Silva Ferreira ${ }^{1}$ \\ Vanessa Bellão Pereira²
}

\begin{abstract}
Resumo:
O objetivo do estudo apresentado neste artigo foi problematizar as particularidades do estado do Pará na efetivação do SUAS (Sistema Único de Assistência Social), a partir de sua territorialidade e das vulnerabilidades sociais às quais está exposto. Tal reflexão é narrada a partir da experiência no Programa Capacita SUAS, nos municípios de Belém do Pará, Castanhal, Marabá e Altamira. As capacitações foram realizadas no período entre maio a agosto de 2014, com a finalidade de atender os objetivos do Programa Nacional de Capacitação do SUAS, que tem, entre suas metas, garantir oferta de educação permanente para qualificar seus profissionais. Os resultados do programa Capacita SUAS, enquanto estratégia da Educação Permanente, são positivos frente à importância de se levar informação e qualificação aos seus trabalhadores, assim como, de se efetivar e garantir o que está posto pela NOB/RH. A pesquisa foi produzida a partir de análise documental e por meio da coleta de dados realizada durante as capacitações. Os alunos registraram as oficinas e os debates realizados, o que permitiu o desenvolvimento deste artigo. Essa valiosa experiência nos revelou, enquanto facilitadoras do Capacita SUAS, a necessidade de continuidade do programa como uma estratégia de educação permanente, que permite aos trabalhadores o nivelamento de conhecimento.
\end{abstract}

Palavras-chave: SUAS. Educação permanente. Território. Políticas públicas. Diversidade.

\begin{abstract}
:
The purpose of this paper is to discuss the particularities of the state of Pará concerning the actualization of SUAS (Unified Social Work System), from its territoriality and the social vulnerabilities to which it is exposed. Such discussion is narrated from the experience of Capacita SUAS Program in Belem do Pará, Castanhal, Marabá and Altamira towns. The training took place from May to August 2014, in order to meet the objectives of the "SUAS National Training Program", whose aims are, among other, to ensure permanent education to qualify its professionals. The results of the Capacita SUAS Program as a Continuing Education strategy are positive, considering the importance of giving information and qualification to its employees, as well as of carrying out and ensuring what is posed by NOB/HR. This research was produce from documental analysis and through data gathering during the trainings. Students registered the classes and the debates carried out, what allowed the writing of this article. This valuable experience
\end{abstract}

\footnotetext{
${ }^{1}$ Docente do curso de Serviço Social da FAl/Adamantina. Mestranda em Meio Ambiente e Desenvolvimento Regional pela UNOESTE/SP. E-mail: silviaaline.ssocial@gmail.com

${ }^{2}$ Docente do CAPACITA Suas pela UNILINS/SP. E-mail: vanessabellão@hotmail.com
} 
disclosed to us, as Capacita SUAS facilitators, the need for continuity of the Program as a Continuing Education strategy, which allows workers' knowledge enhancement.

Keywords: SUAS. Continuing education. Territory. Public policy. Diversity.

\section{Introdução}

As inovações propostas pela Política Nacional de Assistência Social - PNAS/2004 e pelo Sistema Único de Assistência Social - SUAS/2005 (BRASIL, 2005) envolvem questões conceituais e temas de gestão da política, assim como, dos serviços de proteção social. Nesta perspectiva, a educação permanente vem assumindo um lugar estratégico e fundamental para a garantia da formação qualificada dos atores sociais, pois permite que os profissionais do SUAS façam reflexões sobre sua prática profissional, articulando-as com suas vivências no território e na subjetividade da sua essência humana, objetivando garantia e efetivação de direitos.

Em decorrência do processo de implantação e implementação do SUAS, no atual estágio de desenvolvimento, tornam-se cada vez mais visíveis os desafios referentes ao fortalecimento da gestão e à qualificação dos serviços, cujo enfrentamento pressupõe a organização efetiva da Vigilância Socioassistencial. Nesse contexto, as Orientações Técnicas da Vigilância Socioassistencial de 2013 afirmam que:

[...] os processos de produção, análise e utilização de informações ganham relevância na medida em que possibilitam qualificar a intervenção dos agentes públicos de forma que suas ações produzam processos e resultados mais condizentes com as expectativas e necessidades da população em geral e, em particular, dos segmentos sociais mais vulneráveis (BRASIL, 2013a).

A Vigilância deve ser capaz de ampliar a capacidade de Proteção e Defesa de Direitos inerentes à concepção do SUAS, daí advém a importância que a NOB SUAS 2012 reafirma sobre a Vigilância Socioassistencial dada na LOAS - Lei Orgânica da Assistência Social e na PNAS - Política Nacional da Assistência Social. A LOAS, alterada pela Lei 12.435/2011, afirma, em seu Art. 2ㅇ:

A assistência social tem por objetivos a vigilância Socioassistencial, que visa analisar territorialmente a capacidade protetiva das famílias e nela a ocorrência de vulnerabilidade, de ameaças, de vitimizações e danos, apontando para a importância da Vigilância Socioassistencial como objetivo da política da assistência social (BRASIL, 2011). 
Para tanto, no Capítulo da Organização da Gestão, em seu Art. 6으, a LOAS declara que o SUAS tem o objetivo de afiançar a vigilância socioassistencial e a garantia de direitos. Destaca-se, ainda, no Art 6으, que: "a vigilância socioassistencial é um dos instrumentos das proteções da assistência social que identifica e previne situações de risco e vulnerabilidade social e seus agravos no território." (BRASIL, 2011).

Vale a pena destacar que a noção de território ultrapassa os limites geográficos e deve ser baseada no reconhecimento das capacidades criadas, coletivamente, no território, enquanto espaço de vivência com características políticas, econômicas e culturais. Ao se abordar o conceito de território, deve-se considerar a perspectiva trazida por Milton Santos (2007), avaliada como a mais adequada para a discussão sobre vigilância.

Para Santos (2007), o território usado, visto como uma totalidade, é um campo privilegiado para a análise, pois este revela, de um lado, a estrutura global da sociedade, e, de outro, a própria complexidade de seu uso.

O tema tratado neste artigo surgiu da experiência como facilitadores do Programa Capacita SUAS do Ministério de Desenvolvimento Social e Combate a Fome - MDS, no Estado do Pará, nos anos de 2014 e 2015. A metodologia utilizada para coletar os dados foi a análise documental e o recolhimento de depoimentos/relatos dos cursistas do Capacita SUAS, nas cidades de Belém do Pará, Marabá, Altamira e Castanhal, no estado do Pará.

O programa é resultado da organização da Assistência Social enquanto Política Social Pública, que tem por objetivo a promoção do indivíduo e a garantia de direitos por meio de ações organizadas por um sistema único descentralizado. O Programa Nacional de Capacitação do SUAS é uma estratégia utilizada para apoiar os Estados e o Distrito Federal na execução dos Planos Estaduais de Capacitação do SUAS, visando ao aprimoramento da gestão e à progressiva qualificação dos serviços e benefícios socioassistenciais. O Capacita Suas tem como objetivo promover a capacitação dos gestores, trabalhadores e conselheiros da Assistência Social, que, pautada pela Gestão do Trabalho e pela Educação Permanente, exige um novo perfil de trabalhadores: éticos, críticos, reflexivos e comprometidos com o exercício profissional.

Tal programa é organizado pela Política Nacional de Educação Permanente PNEP/2013. Instituída pela Resolução no 04, de 13 de março de 2013, estabelece a perspectiva político-pedagógica, fundada no princípio da educação permanente (BRASIL, 
2013b). Esta perspectiva inovadora resulta de um amplo debate que envolve gestores das três esferas - trabalhadores, conselheiros e usuários - encontrados ao longo de toda a trajetória da Política de Assistência Social. Esta política, que exige do Estado um forte papel de execução, com vistas à profissionalização do SUAS, possui três princípios relevantes a serem seguidos: a interdisciplinaridade, a aprendizagem significativa e a historicidade. Dessa forma, as ações de formação e capacitação do Capacita SUAS abarcam questões filosófico-científicas e ético-políticas, relacionadas aos princípios e aos fundamentos da análise do sujeito e do projeto social que lhe confere tal identidade, fazendo a mediação dessas questões com as de caráter técnico-operativo. Compreendem, ainda, processos de atualização e renovação contínua das práticas e atitudes profissionais das equipes de trabalho, a partir da afirmação de valores e princípios e do contato com novos aportes teóricos, metodológicos, científicos e tecnológicos disponíveis.

Em cumprimento aos objetivos da Política de Educação Permanente, por meio da efetivação do Capacita SUAS, foram desenvolvidos, no curso, espaços de discussão que permitiram o fomento debates acerca das características peculiares territoriais, sociais e ambientais do estado em questão, com ressalvas para o fator amazônico e sua influência nos serviços sócioassistenciais ofertados, devido às enchentes que desalojam as famílias em determinada época do ano, quando ocorrem as cheias dos rios

Os grupos de debate foram compostos por trabalhadores do SUAS, sendo estes assistentes sociais, psicólogos, pedagogos, bacharéis em direito, sociólogos, administradores e gestores de políticas públicas, o que possibilitou uma reflexão acerca das expressões da questão social no território do Pará, assim como, sobre as respostas que as políticas públicas têm ofertado às mesmas, como estratégia de enfrentamento.

Compreender as diferentes expressões da questão social brasileira é, inegavelmente, imprescindível, pois estas emergem cotidianamente, por meio das multifacetadas imbricações contidas no processo de exclusão social. Evidência-se que tais expressões se dão no concreto dos territórios de vivência, nos inúmeros municípios brasileiros, distintos em suas dimensões populacionais, em suas áreas geográficas e em suas configurações econômicas, políticas, culturais e sociais. 
Neste estudo, foram destacados municípios do Estado do Pará, que elucidam características peculiares em relação aos do restante do país, já que se trata de um território extenso, com uma população rural numerosa e características ambientais ímpares. É nesse contexto que surgem questionamentos quanto ao significado da territorialização ou, ainda, da pertinência de se inserir, na análise das expressões da questão social, a dimensão territorial e sua interlocução com as políticas sociais.

O Estado do Pará é o mais populoso da região norte e o segundo maior do país em extensão territorial. Conta com uma população de 7.581.051 habitantes (IBGE/2010). Sua capital, Belém, reúne, na região metropolitana, cerca de 2 milhões e 100 mil habitantes, sendo a mais populosa do estado, seguida da região de integração do Baixo Amazonas, com 650.446 habitantes. Traz características peculiares em comparação com o restante do território nacional, como: o fator amazônico, que inclui as longas distâncias existentes entre as regiões e as horas ou dias necessários de viagem para o deslocamento entre elas; riquezas e pobrezas regionais; e uma grande variedade étnica, cultural e ocupacional, isto é, populações indígenas, quilombolas, ribeirinhos, caboclos, seringueiros, em síntese, os povos das florestas, que, historicamente, têm construído suas presenças no grande Estado do Pará, que possui uma exuberância de matas, fauna, flora e riquezas naturais.

Compreende-se que a questão socioterritorial se apresenta como um eixo central para se decifrar a complexidade e os desafios da proteção social no Estado do Pará. Dessa forma, faz-se necessário um debate sobre: a importância da Política de Assistência Social e sua aproximação das configurações produzidas no âmbito do desenvolvimento capitalista; e como o SUAS tem sido efetivado frente à vertente territorial e aos múltiplos fatores que levam os indivíduos e os coletivos a situações de vulnerabilidade social.

São abordados, neste artigo, os objetivos da Politica Nacional de Educação Permanente e, em seguida, a importância da educação permanente para a efetivação da Política de Assistência Social e a integralidade do SUAS. São apresentados, também, dados sociodemográficos do Estado do Pará, bem como, as considerações finais acerca do processo de Capacitação dos trabalhadores do SUAS.

\section{Política nacional de educação permanente}


A educação permanente é resultado de um processo de discussões e da organização dos trabalhadores do SUAS. Tal política tem por objetivo colaborar com a profissionalização do SUAS, que requer de seus gestores, trabalhadores e conselheiros novos conhecimentos, habilidades e atitudes, frente às necessidades de provisão de serviços e benefícios socioassistenciais mais qualificados e comprometidos com um projeto emancipatório de sociedade. A Politica Nacional de Educação Permanente foi aprovada pelo Conselho Nacional de Assistência Social - CNAS, por meio da Resolução no 04, de 13 de março de 2013 (BRASIL, 2013b).

Como dito anteriormente, a Política de Educação Permanente é resultado da organização da própria Política de Assistência Social, criada por suas legislações, com base na Constituição Federal de 1988 e na LOAS, que, em seu artigo 19, estabelece:

Compete ao órgão da Administração Pública Federal, responsável pela coordenação da Política Nacional de Assistência Social: IX - Formular política para a qualificação sistemática e continuada de recursos humanos no campo da assistência social (BRASIL, 1993).

A Política Nacional da Assistência Social exige a efetivação do Art. 6o da LOAS (alterada pela Lei $\mathrm{n}$ - 12.435/2011), que preconiza que:

[...] a gestão das ações na área de assistência social fica organizada sob forma de sistema descentralizado e participativo, denominado Sistema Único de Assistência Social (SUAS), com os seguintes objetivos: $\mathrm{V}$ - implementar a gestão do trabalho e a educação permanente na assistência social (BRASIL, 2011)

Por fim, a NOB-RH/SUAS-2006 afirma que um dos principais eixos, estabelecidos pela Norma para a Gestão do Trabalho, é a Política Nacional de Capacitação do SUAS, que deverá ser coordenada e financiada pelos Governos Federal, Estadual, do Distrito Federal e dos municípios (BRASIL, 2006).

A PNEP/2013, instituída pela Resolução no 04, de 13 de março de 2013, estabelece uma perspectiva político-pedagógica fundada no princípio da educação permanente, que se apresenta como inovadora, pois possibilita um amplo debate que envolve gestores de três esferas -trabalhadores, conselheiros e usuários - encontrados ao longo de toda trajetória da PAS (BRASIL, 2013b). Essa política exige do Estado um forte papel de execução, com vistas à profissionalização do SUAS, e tem como público-alvo 
trabalhadores do SUAS com nível de escolaridade fundamental, médio ou superior - da rede governamental e não governamental - assim como, os gestores e agentes de controle social no exercício de suas competências e responsabilidades.

\section{A política de assistência social e o território}

Conforme Santos (2007, p. 144), "é impossível imaginar uma cidadania concreta que prescinda do componente territorial", assim, é impossível pensar o enfrentamento das atuais desigualdades estruturais do país, sem se considerar a direção políticoeconômica que sustenta e hegemoniza o processo de produção, apropriação e domínio do espaço socialmente produzido. Nesse sentido, segundo Andrade:

[...] território usado, ao mesmo tempo em que expressa um conteúdo específico, arrasta, em seu movimento socioterritorial, a totalidade do modo de (re)produção social de uma sociedade num determinado tempo histórico. Portanto, as históricas contradições de classes resultam nas inúmeras desigualdades, expropriações e violações de direitos que se acumulam secularmente na sociedade brasileira, encontrando-se superpostas, objetivadas e encravadas na realidade particular de cada lugar (ANDRADE, 2012, p.65).

Frente ao exposto, busca-se refletir sobre a complexidade da incorporação do território nos eixos estruturantes do SUAS, pois o território é um espaço permeado pelo contexto político e econômico de desigualddaes e exclusões a que os indivíduos estão expostos.

A perspectiva socioterritorial foi incorporada à Política Nacional de Assistência Social apenas em sua segunda versão, de 2004 (BRASIL, 2005). Em sua primeira apresentação, a referência ao território foi periférica. Território, nesse caso, foi tratado como solo da Pátria ou das comunidades, entendidas como microterritórios.

Com a PNAS/2004, o tratamento relativo ao território adquiriu outro status e a perspectiva socitoterritorial passou a ser assumida como um dos eixos estruturantes, incorporados a essa política pública. Em decorrência dessa definição, foram concebidos os Centros de Referência de Assistência Social (CRAS), situados nos territórios em que havia, e ainda há, registro de vulnerabilidade e risco social (BRASIL, 2005).

Em relação à conceituação de território, Santos se posiciona da seguinte forma:

O território não é apenas o resultado da superposição de um conjunto de sistemas naturais e um conjunto de sistemas de coisas criadas pelo homem. 0 
território é o chão e mais a população, isto é, uma identidade, o fato e o sentimento de pertencer àquilo que nos pertence. $O$ território é a base do trabalho, da residência, das trocas materiais e espirituais e da vida sobre os quais ele influi (SANTOS, 2000, p. 96).

Koga (2003, p. 33) corrobora a afiramtiva de Santos, ao assinalar que o território "representa o chão do exercício da cidadania, pois cidadania significa vida ativa no território, onde se concretizam as relações da vizinhança, e solidariedade, as relações de poder."

Observados os dois conceitos, é possível identificar o processo de superação do limite teórico posto ao conceito de território, quando este é entendido apenas como um recorte de área geográfica. Território entendido em sentido amplo não é um pedaço de terra, de mar ou um espaço aéreo. Território é chão e mais gente, identidade, sentimento, vida ativa, exercício de cidadania. É importante lembrar que, no mundo virtual, tão evidente nos dias atuais, limita-se ou mesmo descarta-se a representação material dos territórios.

No âmbito da assistência social, a perspectiva socioterritorial é assumida como a possibilidade de assegurar maior ampliação do seu alcance, visando a estender ações de proteção social a um maior número de brasileiros em situação de vulnerabilidade e risco social. Na atual PNAS, a incorporação da perspectiva socioterritorial fundamenta uma determinada forma de conceber e operacionalizar a assistência social. Essa perspectiva é explicitada em vários pontos da PNAS, como se pode constatar a seguir:

A Política Nacional de Assistência Social traz sua marca no reconhecimento de que para além das demandas setoriais e segmentadas, o chão onde se encontram e se movimentam setores e segmentos fazem a diferença no manejo da própria política, significando considerar as desigualdades socioterritoriais da sua configuração (BRASIL, 2005, p. 14).

É necessário relacionar as pessoas e seus territórios, no caso os municípios que, do ponto de vista federal, são a menor escala administrativa governamental. 0 município, por sua vez, poderá ter territorialização intraurbana, já na condição de outra totalidade que não é a nação (BRASIL, 2005, p. 15).

Ao agir nas capilaridades dos territórios e se confrontar com a dinâmica do real, no campo das informações, essa política inaugura uma outra perspectiva de análise ao tornar visíveis aqueles setores da sociedade brasileira, tradicionalmente tidos como invisíveis ou excluídos das estatísticas - população em situação de rua, adolescentes em conflito com a lei, indígenas, quilombolas, idosos, pessoas com deficiência (BRASIL, 2005, p. 16).

[...] ao invés de metas setoriais a partir de demandas ou necessidades genéricas, trata-se de identificar os problemas concretos, as potencialidades e 
as soluções, a partir de recortes territoriais que identifiquem conjuntos populacionais em situações similares, e intervir através das políticas públicas, com o objetivo de alcançar resultados integrados e promover impacto positivo nas condições de vida (BRASIL, 2005, p. 44).

A concepção de território contida na PNAS, conforme pode ser observado, sinaliza para os seguintes elementos básicos de materialização da referida política: o reconhecimento da existência de desigualdades territoriais a serem consideradas; a necessidade de se perceber a existência de uma territorialização intraurbana, ou seja, de recortes dentro dos espaços urbanos e dos municípios; a proposta de imprimir visibilidade a segmentos populacionais excluídos; a constatação de que, nos territórios, além de problemas e necessidades, também existem potencialidades e soluções; e, finalmente, a certeza de que a abordagem a partir de recortes territoriais permite a identificação de semelhanças e diferenças na realidade dos usuários da assistência social, de modo asuperar a prática de generalização em situações que exigem um tratamento diferenciado.

Para a atuação nos territórios, a PNAS propõe a criação dos Centros de Referência de Assistência Social, implantados nos espaços socioterritoriais com registro de vulnerabilidade e risco social. Os CRAS têm a responsabilidade da Proteção Social Básica, ou seja, "o serviço de acompanhamento de grupos territoriais até 5.000 famílias sob situação de vulnerabilidade, em núcleos de até 20.000 habitantes" (BRASIL, 2005, p. 95). Esses grupos familiares são as famílias de referência, ou seja, as que vivem em áreas caracterizadas como de vulnerabilidade, definidas a partir de indicadores estabelecidos por órgão federal, pactuados e deliberados.

Pensar a Política de Assistência e os impactos territoriais através das expressões da questão social e de seu resultado histórico remete à perspectiva de que o território se configura como um elemento relacional na dinâmica do cotidiano de vida das populações. O fato de o território estar tão presente no cotidiano e na vida das pessoas evidencia que a história não se faz fora do mesmo, já que não existe sociedade fora do espaço. Neste ponto, elucida-se a discussão realizada pelos operadores da política de assistência social, que relatam as dificuldades em relação às distâncias entre os territórios, visto que, com frequência, os técnicos precisam se deslocar por extensões de, aproximadamente, 200 $\mathrm{km}$, na maioria das vezes, por rios, o que leva as as equipes técnicas a disponibilizarem vários dias para tais viagens. 
O estado do Pará exige uma vasta discussão sobre os aspectos territoriais e seus impactos para as políticas públicas, quando se toma por base o conceito de território proposto pela PNAS, que estabelece a territorialização como eixo norteador da política de assistência social.

\section{Breve caraterização do Estado doPará}

Figura 1 - Mapa do Estado do Pará com as suas divisões territoriais de integração.

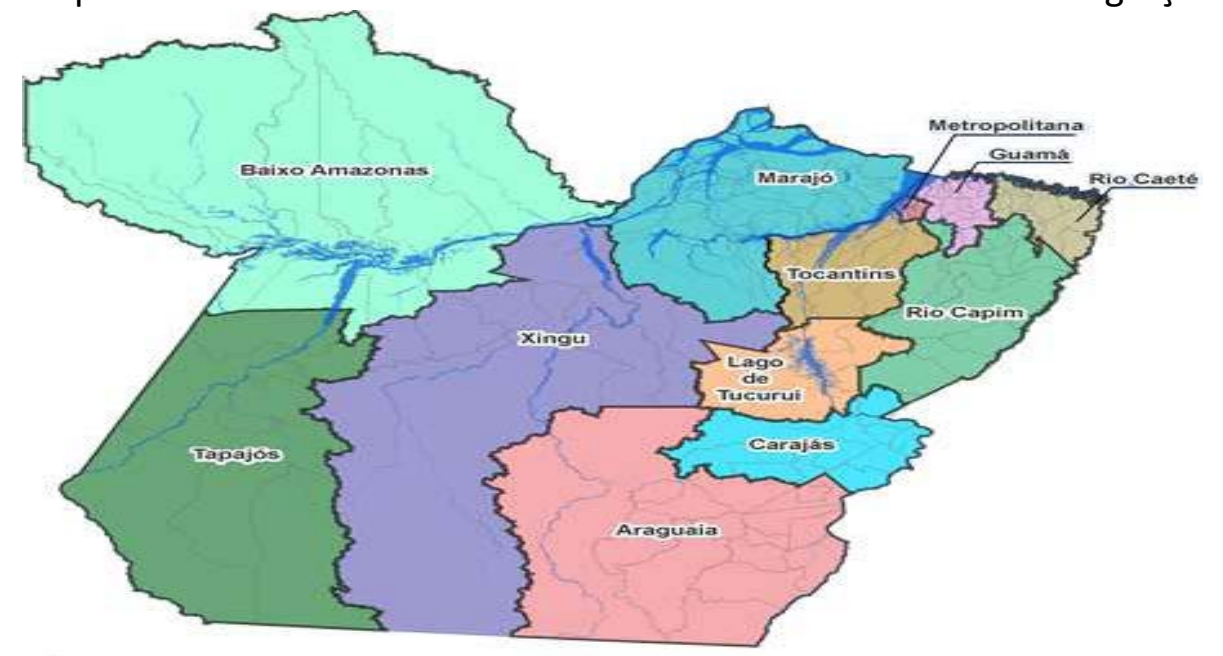

Fonte: Pará (2015).

O Estado do Pará está localizado na Região Norte do Brasil e apresenta o maior número de habitantes da região: 7.581.051 no total; 5.191.559 na zona urbana, e 2.389.492, na área rural. De acordo com IBGE (2010), é o segundo maior Estado do Brasil em extensão territorial, com $1.247 .689 .515 \mathrm{~km}^{2}$, e apresenta densidade demográfica de $5.66 \mathrm{hab} . / \mathrm{km}^{2}$.

O Pará possui 144 municípios e encontra-se organizado em 12 Regiões de Integração, com características específicas, já mencionadas anteriormente. Como esta é uma região do país com muitas peculiaridades territoriais, é importante chamar a atenção para os deslocamentos dentro do Estado, que, em sua maioria, são feitos por meio pluvial, de forma simples e rude. Durante o inverno, o estado passa por grandes períodos de enchentes. Nesse contexto, há grande dificuldade em ofertar políticas públicas de qualidade e que atendam a essa imensidão territorial.

Dados da organização não governamental (ONG), Comunidades Quilombolas no Brasi, indicam que existem 240 comunidades quilombolas no Estado do Pará, distribuídas pelas várias regiões do Estado, algumas mais próximas e outras mais distantes, de difícil 
acesso, como as do Baixo Amazonas. A população indígena é de 37.681 habitantes (PARÁ, 2015 , p. 7). De acordo com as leituras realizadas, os dados sobre a população indígena variam conforme a fonte consultada. Assim, os valores quantitativos informados não são equiparados, pois, enquanto o Conselho Indigenista Missionário informa que há 37.681 pessoas indígenas, o Censo demográfico 2010 do IBGE, que utiliza a metodologia em que as pessoas autodeclaram cor e/ou raça, aponta que, no Pará, há 51.217 pessoas indígenas. Vale destacar que, dentre as pessoas indígenas, que moram em área indígena, com até 10 anos de idade, 7\% não apresentam registro civil e 34\% não são alfabetizadas.

A diversidade cultural exige que o Estado se atente às peculiaridades de cada área regional, tanto no que diz respeito às suas riquezas para o crescimento econômico, quanto às expressões da questão social para a superação e consequente desenvolvimento.

O Estado do Pará, ao mesmo tempo em que é repleto de riquezas naturais, possui 18,42\% (1.396.684) da população em situação de pobreza extrema, o que exige um olhar atento para as necessidades do povo, respeitando as particularidades e peculiaridades regionais.

A gestão do SUAS, no Pará, enfrenta, assim, desafios geográficos, de diversidade étnica e geopolíticos. Isso significa que é fundamental o processo de capacitação continuada para que os trabalhadores estejam preparados para atender toda essa diversidade.

Diante do exposto, pode-se afirmar que essa diversidade permite a implantação do modelo de gestão descentralizado e participativo do SUAS, que remete à compreensão do território como um de seus eixos estruturantes, frente às demandas de uma realidade socioterritorial heterogênea e desigual (PARÁ, 2015, p. 9).

As legislações vigentes (LOAS, PNAS e NOB/SUAS) são claras no que tange à obrigação dos municípios, a partir da descentralização político-administrativa, no sentido de planejar a implantação das políticas públicas, em destaque, aqui, a Política de Assistência Social, a partir do conhecimento aprofundado do território.

Para Koga (2003), o território representa o chão do exercício da cidadania, onde se materializa a presença/ausência dos serviços públicos, o que não significa, simplesmente, o acesso a todos os serviços e com qualidade. 
A afirmação acima, porém, ganha relevância quando interpretada a partir de Milton Santos (1997), que assinala que o território, em si, não é um conceito, pois só se torna um conceito utilizável para análise social, quando é considerado a partir de seu uso, a partir do momento em que é pensado juntamente com os atores que o utilizam. É o uso do território que faz dele o objeto de análise social. A perspectiva territorial incorporada pelo SUAS:

[...] representa outra mudança paradigmática de relevância. As ações públicas da área da assistência social devem ser planejadas territorialmente tento em vista a superação da fragmentação, o alcance da universalidade de cobertura, a possibilidade de planejar e monitorar a rede de serviços, realizar a vigilância social das exclusões e estigmatizações presentes nos territórios de maior incidência de vulnerabilidade e carecimentos (BRASIL, 2008, p. 53).

É importante citar Castro (2003) para exemplificar como a geografia tem se preocupado em discutir a dimensão territorial na perspectiva das políticas públicas. Nesse sentido, a autora afirma que o território se constitui a partir de relações, fundamentalmente, políticas, pois é possível perceber, no conjunto de fatores que resultam, diretamente, da política, a centralidade das dinâmicas territoriais que afetam a organização da base material da sociedade.

Na perspectiva do princípio de territorialização, é importante destacar que o Brasil é um país territorialmente extenso, que possui uma formação societária diversificada, o que afeta, consideravelmente, a elaboração de uma política para todas as diferentes regiões do país, já que cada localidade responderá de forma diferente a essa política. A diversidade territorial é fundamental para o planejamento das ações, pois há, hoje, as mais diversas realidades territoriais que interferem na operacionalização e nos resultados das políticas públicas.

A PNAS destaca uma grande dificuldade para configurar políticas públicas, a fim de minimizar as desigualdades da população brasileira, já que se trata de um país com alta densidade populacional, alto grau de heterogeneidade e desigualdades socioterritoriais e econômicas, o que exige que se agregue "ao conhecimento da realidade a dinâmica demográfica associada à dinâmica socioterritorial em curso" (BRASIL, 2005, p. 43).

Desse modo, é importante destacar a reflexão da pesquisadora Joaquina Barata Teixeira: 
A região amazônica põe um desafio diferente ao princípio da territorialidade. Sua particularidade regional pede especificidades na leitura da realidade social em seu território, e pede a introdução de ativos na potencialização da proteção social no âmbito do SUAS. [...] A proteção social, portanto, tem que tomar etnias e agrupamentos culturais e ocupacionais, (indígenas, quilombolas, ribeirinhos, castanheiros, seringueiros, caboclos), como coletivos sujeitos de direitos e suas culturas como protagonistas da história de resistência na Amazônia (TEIXEIRA, 2013, p. 190).

Teixeira (2013) cita quatro componentes da particularidade amazônica, que já produzem agora e produzirão mais ainda, intercorrências substantivas nas políticas públicas e, naturalmente, no trabalho do SUAS:

I- o território amazônico;

II - as etnias amazônicas e seus diferentes paradigmas culturais;

III - as tensões, violência e conflitos originados da introdução de algumas formas da propriedade na Amazônia, com a presença dominante, no campo, do latifúndio, com grandes impactos sociais e ambientais e a presença imponente, no setor industrial, do enclave, também com impactos sociais e ambientais e suas avassaladoras formas de modernização destrutiva da natureza e da força de trabalho. Para os enclaves da Amazônia se aplicam as observações de Robert Castel [...], quando diz que a empresa era uma máquina de integrar, agora é uma máquina de vulnerabilizar e de excluir, mesmo em suas formas modernizadoras e aparentemente democráticas, como a da gestão participativa, que exige mais do que expertise em determinada atividade. Exige cultura geral e política, dificultando a absorção tanto de jovens como de idosos. Quanto mais poderosa e competitiva uma empresa, diz o autor, mais seletiva ela é, no que estamos de acordo;

IV - os espaços de ausência dos referenciais republicanos[...] (TEIXEIRA, 2013, p. 192)

Nesse sentido, para Nakano (2008, p. 54):

As cidades brasileiras expõem legados históricos que constituem dívidas socioterritoriais acumuladas durante séculos de urbanização segundo padrões desiguais do ponto de vista social, excludente do ponto de vista territorial e predatório do ponto de vista ambiental. Esse quadro de crise urbana aparece em diversos contextos regionais e socioambientais, desde as cidades da zona costeira até aquelas localizadas nas regiões do interior mais recôndito do país.

Conforme o Mapa de Vulnerabilidade Social, a vulnerabilidade está associada não apenas às características socioeconômicas, mas também a outros fatores, como baixos níveis de escolaridade, acesso a serviços públicos, perfis familiares, características demográficas dos grupos sociais e dos setores censitários e aspectos que colocam ou 
podem colocar as pessoas em situações de risco (agravos à saúde, gravidez precoce, jovens vítimas de homicídio, entre outros). Neste contexto, pode-se salientar que as características socioterritoriais das áreas vulneráveis demonstram a dificuldade de se atingir o acesso de toda a população às políticas públicas e do Estado, ao mesmo tempo em que evidenciam as prioridades do território para o enfrentamento das situações de vulnerabilidade.

Para o reconhecimento da realidade territorial, é importante destacar a vigilância socioassistencial, cujo objetivo é apoiar atividades de planejamento, organização e execução de ações desenvolvidas pela gestão e pelos serviços, de modo a produzir, sistematizar e analisar informações territorializadas. Para tanto, deve-se dotar os trabalhadores de conhecimento.

É primordial, portanto, que os atores sociais exerçam sua função de mediadores de direitos sociais e visem, em suas ações, ao planejamento, à avaliação e ao monitoramento, a partir da perspectiva territorial. Todavia, de acordo com Fernandes (2007 apud MARCONDES, 2013), vale ressaltar a necessidade de se repensar as condições de trabalho dos trabalhadores do SUAS, pois políticas de formação de trabalhadores adquirem sentido quando acompanhadas por políticas de qualificação dos espaços sócioocupacionais e de suas condições.

Esta é uma tarefa desafiadora, que exige priorização, esforço, investimento e o desenvolvimento de capacidades para utilização das informações.

\section{Capacita SUAS e a diversidade territorial no Estado do Pará}

O Capacita SUAS, no Pará, alcançou cerca de 1500 trabalhadores capacitados, distribuídos em 14 polos em todo o estado. Os cursos ofertados foram: o Curso I dos Provimentos dos Serviços Socioassistenciais, e o Curso II de Gestão Financeira e Orçamentária do SUAS (BRASIL, 2008).

De acordo com os relatos dos profissionais, são muitos os obstáculos enfrentados para a implantação e implementação do SUAS no Estado.

Segundo o diagnóstico dos municípios de Belém do Pará, Marabá, Castanhal e Altamira, locais onde as pesquisadoras ministraram o Capacita SUAS, há necessidade de educação permanente e de efetivação dos princípios norteadores do SUAS. Dos 
municípios citados no presente artigo, todos possuem distritos cujas distâncias variam de 200 a 950 km, que são percorridos por estradas de terra precárias e/ou rios.

Chama a atenção o município de Altamira, que, além de ser o terceiro maior município do mundo, é o maior do Brasil, e, caso fosse um estado, seria maior do que o Ceará e o Acre. Altamira possui um distrito a $950 \mathrm{~km}$ de distância, Castelo dos Sonhos, que faz divisa com o Estado do Mato Grosso, além de ser sede da construção da Usina Hidrelétrica de Belo Monte, que será a terceira maior usina do mundo e a única, totalmente, brasileira. As obras da Hidrelétrica de Belo Monte causaram um crescimento populacional no município, de 100 mil para 150 mil habitantes, pois milhares de trabalhadores e migrantes acorreram para a região à procura de trabalho e melhores condições de vida. No entanto, essa construção causou um enorme impacto sobre os serviços públicos, que já não eram de excelência e, agora, enfrentam grandes desafios para a efetivação de serviços mínimos e de qualidade. Uma característica notória do município é sua hidrografia, pois Altamira está cravada às margens do Rio Xingu, com sua série de afluentes e cachoeiras que se distribuem por toda a região.

Marabá possui $29 \%$ de seu território protegido por unidades de conservação. 0 município abriga três terras indígenas, com 1,5 mil integrantes dos povos Gavião Parkateyé, Suruí Aykewara e Xicrin do Catete. Em 73 assentamentos rurais, que totalizam 380 mil hectares, viviam 6.076 famílias, em 2006. É uma cidade desenhada tanto social quanto espacialmente, em consequência das experiências urbanísticas que resultaram em núcleos com configurações diferenciadas, em razão da organização das ruas - espontânea ou planejada - e da utilização do solo como componente de negociação entre os diferentes grupos sociais existentes. É possível encontrar, na cidade, variadas manifestações de separação socioespacial, com diferentes gradientes definidos em função da participação de agentes na produção do espaço urbano. Outra característica é a maior ou menor permanência de migrantes no território. Eles podem estar concentrados dentro de uma folha da Nova Marabá, no entorno do bairro de condomínios e nas propriedades muradas da Cidade Nova, ou em meio à inundação na Velha Marabá. Há manifestação mais conspícua nas áreas de mistura de perfil populacional, e mais oculta nas periferias formadas ao redor dos bairros dotados de infraestrutura e com maior valorização imobiliária. 
Outra característica importante é existência de populações ribeirinhas e indígenas. Os profissionais participantes relataram as mais diversas dificuldades de trabalho. No entanto, um ponto de destaque, no âmbito das oficinas e discussões em grupo, foi a importância do território no processo de planejamento. A territorialização precisa ainda ser muito discutida com os trabalhadores do SUAS no Estado do Pará, visto que a peculiaridade deste estado sobressalta os olhos. Nesse panorama, há populações que podem ser chamadas de "invisíveis", ou seja, as que a política pública ainda não alcançou, que não têm seus direitos assegurados.

Diante do exposto, levando em consideração as características e peculiaridades geográficas que a região apresenta, cabe ao Estado o desafio de desenvolver ações que atendam as diversidades encontradas. O grande desafio das Políticas Públicas, principalmente, da Política de Assistência Social, é desenvolver estratégias e garantir investimento público que atenda a pluralidade encontrada.

Outro ponto destacado pelos participantes das capacitações diz respeito às longas distâncias percorridas dentro do próprio Estado e, até mesmo, dentro do município, para se conseguir dar acesso às políticas públicas. Segundo Teixeira, as diversificadas distâncias intermunicipais ocasionam sérios comprometimentos, inclusive, financeiros, ao processo de trabalho e de gestão. No entanto, a autora afirma ainda que as longas distâncias são um bom sinal, pois indicam a existência de um vasto território. Um contraponto desta extensão territorial é que a conta dos custos de toda manutenção e oferta das politicas públicas fica para o Estado.

Um modo de contornar tal peculiaridade seria a oferta de lanchas pela Politica de Assistência Social. De acordo com os relatos dos grupos dos municípios, porém, as lanchas não são preparadas para se locomover na realidade dos rios da região do Pará, pois estes têm muitas pedras, o que acarreta danos às mesmas e, consequentemente, requerem frequentes ações de manutenção, que ficam onerosas ao município. Os veículos são precários ou não são adequados para as estradas e territórios percorridos pelos profissionais. Eles são apropriados apenas para algumas regiões, como a do Marajó, devido às suas ilhas e aos vastos territórios amazônicos. No próprio município de Altamira, há um exemplo dessa complexidade de locomoção, pois, para se chegar ao distrito Castelo dos Sonhos, é necessário viajar de avião. 


\section{Considerações finais}

Considerar os aspectos territoriais do Estado do Pará permite vislumbrar características peculiares, que exigem respostas impares das políticas públicas, de acordo com suas demandas e serviços. Muitas são as discussões em torno do fator amazônico, discussões estas que trazem consensos e debates intensos. O que não se pode deixar de ressaltar, aqui, é que o Estado é resultado de um processo histórico, do qual emergem aspectos que se inserem nas agendas políticas.

Diante do exposto, pode-se afirmar que os resultados do programa Capacita SUAS, enquanto estratégia da Educação Permanente, são positivos, frente à importância de se levar informação e qualificação aos trabalhadores do SUAS, assim como, de efetivar e garantir o que está proposto pela NOB/RH. O momento de capacitação constitui uma oportunidade de troca coletiva muito positiva, para que as equipes possam se fortalecer frente às dificuldades encontradas no cotidiano de trabalho.

O Capacita SUAS contribui para o processo de aprimoramento da gestão do Sistema Único da Assistência Social e da qualificação dos serviços, programas, projetos e benefícios socioassistenciais.

Os profissionais relataram interesse e declararam a importância de realizarem capacitações, pois compreendem que a educação permanente é possibilitadora de aquisição de novos conhecimentos e de ampliação do potencial de enfrentamento das situações contraditórias e dos desafios presentes na realidade, além disso, é um estímulo para buscarem, continuamente, a superação (BOURGUIGNON, 2007 apud MARCONDES, 2013).

Vale destacar que as dificuldades enfrentadas, a diversidade territorial e geográfica, bem como, a riqueza natural, que é belíssima, apresentam situações peculiares e exigem intervenção diferenciada e qualificada dos gestores e trabalhadores do SUAS. Além disso, são muitos os indicadores que colocam a população em situação de vulnerabilidade social nos municípios paraenses.

Para finalizar, é fundamental destacar as colocações da pesquisadora Joaquina Barata Teixeira (2013), quando afirma que, se os gestores da região quiserem deixar um legado de suas gestões, devem se integrar na luta de quilombolas, indígenas e povos da 
floresta por seus direitos. O SUAS, na Amazônia, deve ter uma perspectiva ético-política voltada ao reconhecimento do caráter multiétnico e pluricultural de suas populações.

Aponta-se, então, para a necessidade da continuidade do Programa Capacita SUAS como uma estratégia de educação permanente, que permite aos trabalhadores o nivelamento de conhecimento e informações e evidencia as características peculiares das regiões, ao considerar o território como eixo primordial das ações e levar a uma reflexão da prática profissional da política de assistência social, pelo viés da efetivação e garantia de direitos.

Por fim, enseja-se destacar que o estudo apresentado, neste artigo, é uma pequena contribuição para que os agentes públicos possam debater o fator amazônico e as peculiaridades que o mesmo apresenta para as políticas públicas no Estado do Pará.

\section{Referências}

ANDRADE, I. Território e assistência social: uma análise do Serviço Social a partir da produção social do espaço. 2012. 210 f. Tese (Doutorado em Serviço Social) - Pontifícia Universidade Católica do Rio Grande do Sul, Porto Alegre, 2012.

BRASIL. Lei no 12.435, de 6 de julho de 2011. Altera a Lei no 8.742, de 7 de dezembro de 1993, que dispõe sobre a organização da Assistência Social. Disponível em: <http://www.planalto.gov.br/ccivil_03/_ato2011-2014/2011/lei/l12435.htm. Acesso em: 17 jun. 2016.

BRASIL. Lei no 8.742, de 7 de dezembro de 1993. Dispõe sobre a organização da Assistência Social e dá outras providências. Disponível em: <http://www.planalto.gov.br/ccivil_03/leis/L8742.htm>. Acesso em: 19 jun. 2016.

BRASIL. Ministério do Desenvolvimento Social e Combate à Fome. CapacitaSuas SUAS: configurando os eixos de mudança. Brasília: Instituto de Estudos Especiais da Pontifícia Universidade Católica de São Paulo, 2008. v. 1.

BRASIL. Ministério do Desenvolvimento Social e Combate à Fome. Orientações técnicas da vigilância socioassistencial. Brasília: MDS/SNAS, 2013a.

BRASIL. Ministério do Desenvolvimento Social e Combate à fome. Política nacional de assistência social - PNAS/2004: norma operacional básica - NOB/SUAS. Brasília: MDS, 2005. Disponível em:

<http://www.mds.gov.br/webarquivos/publicacao/assistencia_social/Normativas/PNAS2 004.pdf>. Acesso em: 19 de junho de 2016.

BRASIL. Ministério do Desenvolvimento Social e Combate à Fome. Resolução CNAS no 4, de 13 de março de 2013. Institui a política nacional de Educação Permanente do Sistema Único de Assistência Social - PNEP/SUAS. 2013b. Disponível em: 
<https://conferencianacional.files.wordpress.com/2013/12/cnas-2013-004-13-032013.pdf>. Acesso em: 17 jan. 2016.

BRASIL. Ministério do Desenvolvimento Social e Combate à Fome. Norma operacional básica de recursos humanos do SUAS NOB-RH/SUAS. Brasília: MDS, 2006. Disponível em: $<$ http://www.assistenciasocial.al.gov.br/sala-de-imprensa/arquivos/NOB-RH.pdf $>$. Acesso em: 17 jun. 2016.

CASTRO, I. E. Instituições e território: possibilidades e limites ao exercício da cidadania. Geosul, Florianópolis, v. 18, n. 36, p. 7-28, jul./dez. 2003.

IBGE - Instituto Brasileiro de Geografia e Estatistica. Censo Demográfico. Brasilia. IBGE,2010. Disponivel em: http://www.ibge.gov.br/home/. Acessado em 10/03/2016

KOGA, D. Medidas de cidades: entre territórios de vida e territórios vividos. São Paulo: Cortez, 2003.

MARCONDES, N. A. V. A educação permanente no Sistema Único da Assistência Social: a percepção dos assistentes sociais. 2013. Dissertação (Mestrado em Desenvolvimento Humano) - Universidade de Taubaté, Taubaté, 2013.

NAKANO, A. K. O planejamento e a gestão territorial no Brasil: entre o tecnocratismo e o direito à cidade. In: KOGA, D.; FÁVERO, E. T.; GANEV, E. Cidades e questões sociais. São Paulo: Terracota, 2008. p. 53-68.

PARÁ (Estado). Plano estadual de assistência social. Belém: Secretaria de Estado da Assistência Social, 2015.

SANTOS, M. A dimensão histórico-temporal e a noção de totalidade em geografia. In: . Técnica, espaço, tempo: globalização e meio técnico-científico-informacional. São Paulo: Hucitec, 1997. p. 114-118.

SANTOS, M. O espaço do cidadão. 7. ed. São Paulo: Edusp, 2007.

SANTOS, Milton. Por uma outra globalização - do pensamento único à consciência universal. Rio de Janeiro: Record, 2000.

TEIXEIRA, J. B. A Amazônia e a interface com o SUAS. In: CRUS, J. F. et. al. (Org.). Coletânea de artigos comemorativos dos 20 anos da lei orgânica de assistência social. Brasília: MDS, 2013.

Recebido em: 02/11/2015 